\title{
Assessment of a viability of wind power in Iraq
}

\author{
Osama Tarek Al-Taai ${ }^{1}$, Qassim Mahdi Wadi ${ }^{2}$, Amani Ibraheem Al-Tmimi ${ }^{1}$ \\ ${ }^{1}$ Department of Atmospheric Sciences, College of Science, Al-Mustansiriyah University, Baghdad, Iraq \\ ${ }^{2}$ Al-MamonUniversity College, Department of Electrical Power Technical Engineering, Baghdad, Iraq
}

\section{Email address:}

Aus_tar77@yahoo.com (O. T. Al-Taai), qassiimwadi2014@gmail.com (Q. M. Wadi), d.amani_altmimi@yahoo.com (A. I. Al-Tmimi)

\section{To cite this article:}

Osama Tarek Al-Taai, Qassim Mahdi Wadi, Amani Ibraheem Al-Tmimi. Assessment of a Viability of Wind Power in Iraq. American Journal of Electrical Power and Energy Systems. Vol. 3, No. 3, 2014, pp. 60-70. doi: 10.11648/j.epes.20140303.12

\begin{abstract}
Wind energy is now being used in almost every country of the world as an important and pollution free renewable source of energy. This study deals with the feasibility of utilizing winds in generating electricity in Iraq by using the daily average wind speed data since (1/4/2011 to 1/4/2012) for fifteen stations from different regions have been selected for this purpose and for three height $(12,50,100 \mathrm{~m})$ and applied it with wind turbine $(3 \mathrm{Kw})$. The wind power and the wind power density for the selected stations have been calculated and the maximum values at Basrah (Albrjsuh), the medium values at Baghdad (Abughraib) and the lowest values in northern region Mosul (Bashiqah). Byusing the graphical method to calculate the Weibull distribution .the highest values foe Weibull parameters at Basrah (Albrjsuh), the medium values at Baghdad (Abughraib) and the lowest values in Mosul (Bashiqah). The regression statistical analysis correlation was found for all stations and the most effective values was in at Basrah (Albrjsuh), the medium values at Baghdad (Abughraib) and the lowest values was Mosul (Bashiqah).
\end{abstract}

Keywords: Wind Power, Average Daily Wind Speed, Graphical Method, Regression Statistical Analysis, Iraq

\section{Introduction}

Renewable energy refers to energy resources that occur naturally and repeatedly in the environmental where it can be harnessed for human benefit that poses no major environ mental problems. Wind power is one of leading ones among the new, renewable, clean and cheap resource. It describes the processes by which the wind is used to generate mechanical power or electricity by wind turbines which convert the kinetic energy in wind in to mechanical power. This mechanical can be used for specific tasks such as grinding grain, pumping water, or can convert this mechanical power by generator in to electricity. The total quality of this source is extremely large and various with time at any given location [1]. Iraq is an oil country, but this does not prevent the possession of other resources are inexhaustible renewable energies such as solar, hydro and wind power. This research includes wind characteristics and assesses the wind power in Iraq, using the distribution of Weibull and the possibility of using it for generating electricity.

\subsection{The Wind Power}

Calculations of wind power are derived from the equation for kinetic energy $(K E)$, which is:

$$
K E=\frac{1}{2} m v^{2}
$$

Where $m$ is mass, $v$ is acceleration, Air mass is equal to the product of its density and volume. Volume is dependent on the area through which the air is passing, the speed with which it is moving, and the amount of time it travels. Air mass can therefore be calculated as:

$$
m=\rho \cdot A \cdot v \cdot t
$$

Where $\rho$ is the air density $(1.225 \mathrm{~kg} / \mathrm{m} 3$ dry air at $1 \mathrm{~atm}$. and $\left.15^{\circ} \mathrm{C}\right), A$ is the area through which the air passes, $v$ is wind speed and $t$ is time. Since power is energy divided by time, the equation for wind power $(W P)$ can be written as [2]:

$$
W P=\frac{1}{2} \rho \cdot A \cdot v^{3}
$$

\subsection{Wind Power Density}

Wind power density is the amount of wind power available per unit of area perpendicular to the wind flow. In practice, wind power density is used to estimate the 
potential electrical output of a wind farm once the area swept by wind turbine rotors and the power system efficiency are known. The equation for wind power density $(W P D)$ is simply the wind power (equation3) divided by the area, or [2]:

$$
W P D=\frac{1}{2} \rho v^{3}
$$

The best wind capacity is the density of wind capacity (Wind Power Density), because it will gives a clear picture of how to distribute wind speed on average (mean) and this quantity can be estimated in practice by using (Weibull Distribution) which it depends on the two parameter $(c)$ scale and $(k)$ shape parameters, where $\Gamma$ Gamma function $[3,4]$ :

$$
W P D=\frac{1}{2} \rho c^{3} \Gamma\left(\frac{1+3}{k}\right)
$$

\subsection{Vertical Estimation of Wind Speed Using the Power-Law Model}

As described above, winds are slowed by friction at the earth's surface, so that wind speeds tend to be greater at higher elevations. For regions with relatively level terrain and little vegetation, the method most commonly used to obtain this extrapolation is the $1 / 7$ power-law model. The equation of the $1 / 7$ power-law model is:

$$
\frac{v(Z)}{v\left(Z_{0}\right)}=\left(\frac{Z}{Z_{0}}\right)^{\frac{1}{7}}
$$

Where $Z$ is the height at which the wind speed is to be estimated, $v(Z)$ is the wind speed to be estimated, and $Z_{0}$ and are $v\left(Z_{0}\right)$ the reference height and wind speed, respectively [5].

\subsection{Frequency Distribution of Wind Speed}

The wind speed probability density distributions and their functional forms represent the major aspects in wind related literature. The probability distributions most commonly used are those of Weibull and Rayleigh [6]. The Weibull distribution has been found to fit a wide collection of recorded wind data. The variations in wind velocity are characterized by the two functions; the probability density function and the cumulative distribution function. Obtaining the Weibull density distribution is necessary to determine the shape $(k)$ and $\operatorname{scale}(c)$ parameters, the common methods for determining $k$ and care: graphical, standard deviation, moment, maximum likelihood and energy pattern factor methods.

In this research we applied the two methods, Graphical which is one of the most reliable ways to get real results close to the observed, and a new method called energy pattern factor method $(E P F)$.The concept of this method is useful in calculating the available energy in the wind along with the knowledge of the annual or monthly wind speed. It is also useful in choosing a location with limited wind data, because long-term data from neighboring sites can be correlated with one-site short-term measurements.

Graphical method is another way to determine the $k$ and $c$ from Weibull distribution [7]. We transform the cumulative distribution function into a linear form, adopting logarithmic scales. The expression for the cumulative distribution of wind velocity can be rewritten as

$$
1-F(v)=e^{-(v / c)^{k}}
$$

Considering the logarithm twice, we get

$$
\ln \{-\ln [1-F(v)]\}=k \ln (v)-k \ln c
$$

Where $F(v)$ the probability density function, $k$ the shape parameter, $c$ the scale parameter, By Plotting different values of $\ln [-\ln (1-F(v)]$ vs. $\ln (v)$, a straight line is fitted to the points. The slope of line is, $k$ and the intercept on the $\ln [-\ln (1-F(v)]$ axis is $-k \ln c$. The scale parameter:

$$
c=e^{\left(-\frac{y-\text { intercept }}{k}\right)}
$$

\section{Materials and Methodology}

\subsection{Study Area and Data Collection}

The data used in this study are the monthly average of daily values of wind speed at $3 \mathrm{~m}$ was obtained from ministry of agriculture for locations distributed in different regions in Iraq [8], as shown in figure (1), the stations are [Mosul (Bashiqah), Kirkuk (Daquq), Salahaldeen (Tikrit), Dealaa (Khalis), Baghdad (Abughraib), Anbar (Aldawar), Wasat (Essaouira), Karbla - Lake Razzaza, Babel (Kifli), Qadisiyah (Dewaneia), Najaf (Mashkhab), Mayssan (Ekhala), The-Qar ( Shatrah), Basrah (Albrjsuh)] as shown in table(1).

Table 1. Stations Sequences from North to South.

\begin{tabular}{|lll|l}
\hline $\begin{array}{l}\text { Stations Sequences } \\
\text { from N to S }\end{array}$ & $\begin{array}{l}\text { Latitude } \\
\text { (N) }\end{array}$ & $\begin{array}{l}\text { Longitude } \\
\text { (E) }\end{array}$ & $\begin{array}{l}\text { Sea Level Altitude } \\
\text { in Meters }\end{array}$ \\
\hline Mosul (Bashiqah) & 364509 & 433388 & 228.0 \\
Kirkuk (Daquq) & 351693 & 444297 & 227.9 \\
Salahaldeen (Tikrit) & 346528 & 436361 & 116.0 \\
\hline Dealaa (Khalis) & 337517 & 446222 & 40.9 \\
Baghdad (Abughraib) & 333221 & 442393 & 30.4 \\
Anbar (Aldawar) & 332757 & 430208 & 45.6 \\
Wasat (Essaouira) & 330045 & 444927 & 27.2 \\
Karbla (Lake & 323320 & 435837 & 49.0 \\
Razzaza) & 323063 & 443916 & 21.1 \\
Babel (Kifli) & 320193 & 448985 & 24.0 \\
Qadisiyah (Dewaneia) & 315327 & 443011 & 19.0 \\
Najaf (Mashkhab) & 314804 & 471125 & 9.0 \\
Mayssan (Ekhala) & 314557 & 461952 & 7.0 \\
\hline The-Qar (Shatrah) & 31.0 \\
\hline Muthna (Khader) & 301732 & 453751 & 7.0 \\
\hline Basrah (Albrjsuh) & 301732 & 470404 & 7.0 \\
\hline
\end{tabular}




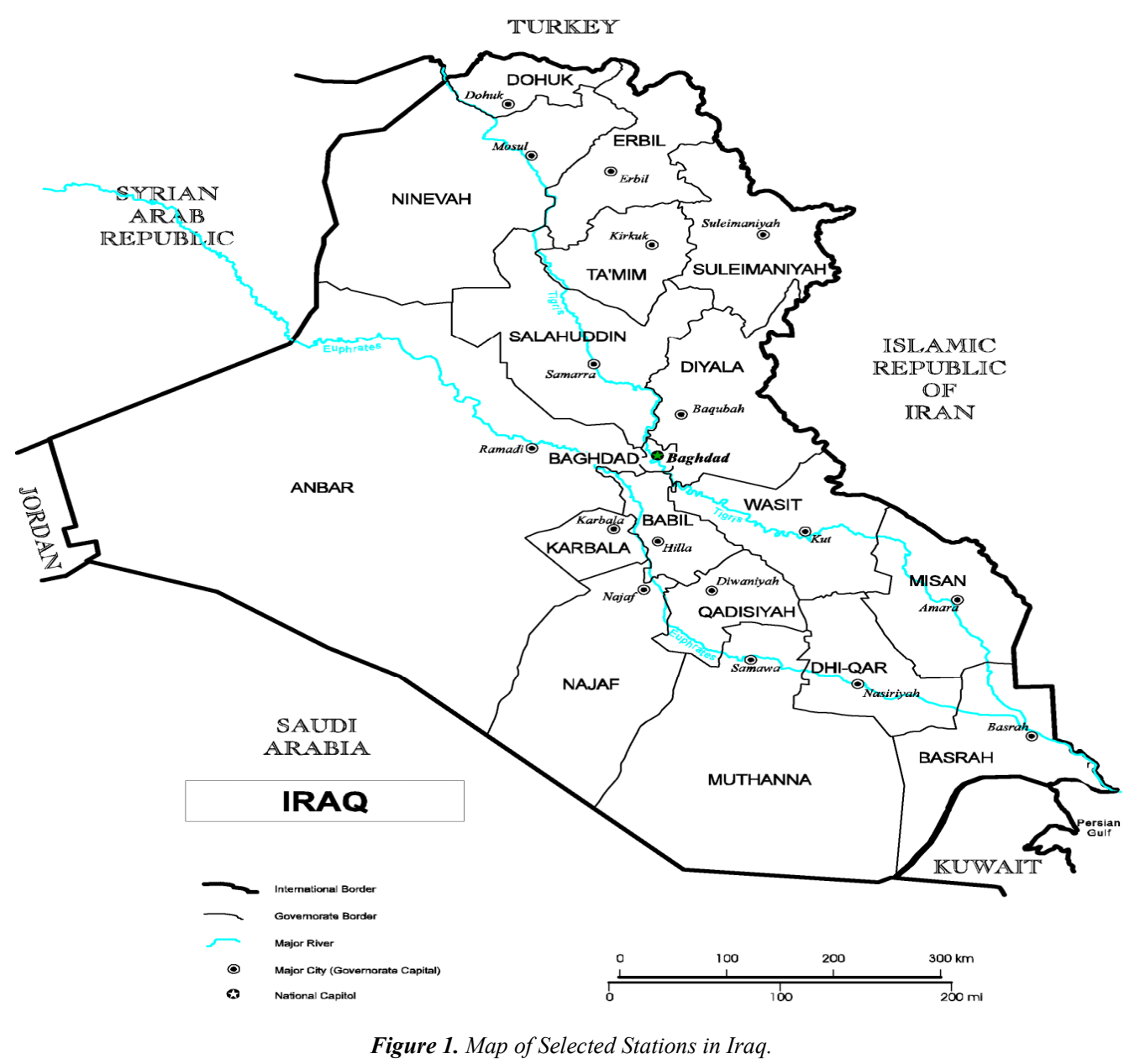

By using eq. (6) we calculated the wind speed in three high $(12,50,100 \mathrm{~m})$ as shown in figures $(2,3,4)$ and table (2).

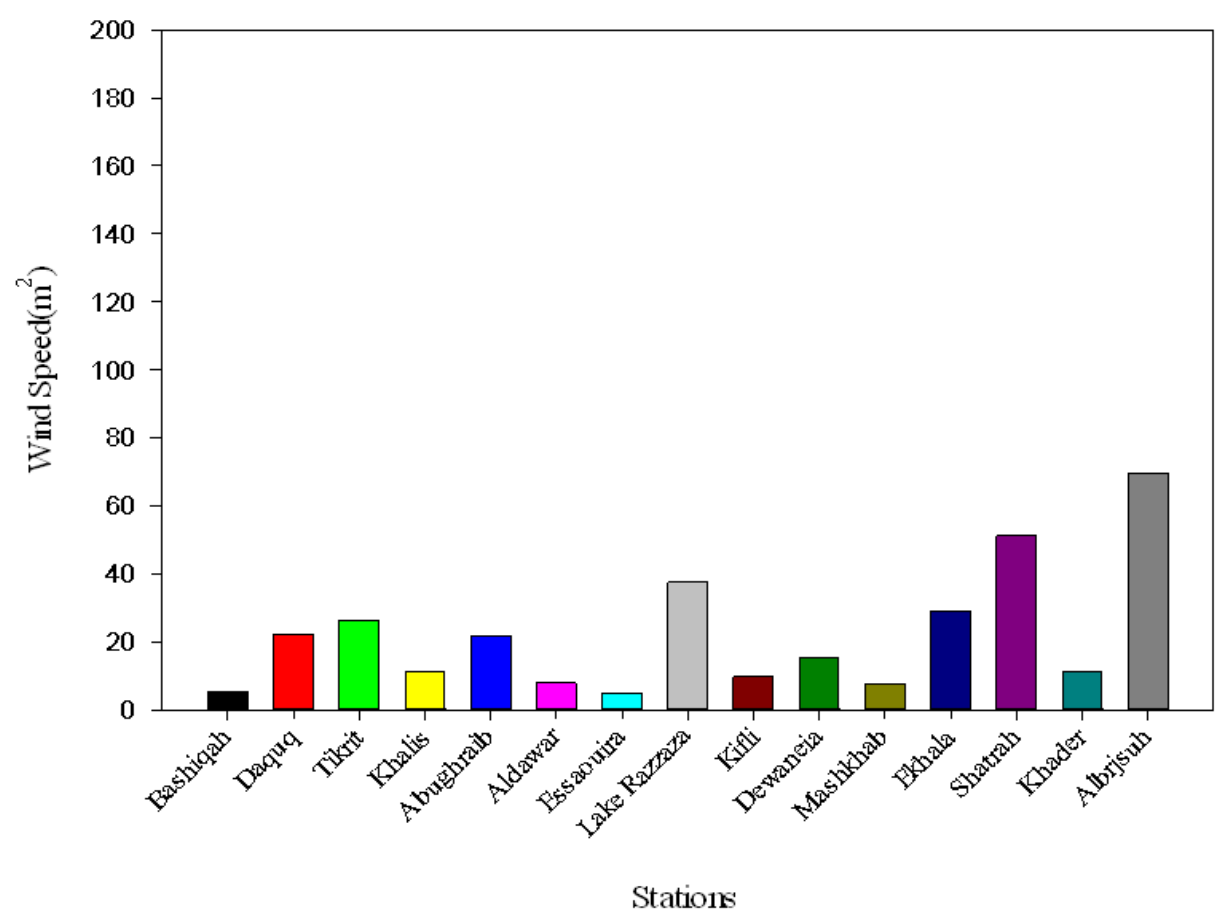

Figure 2. Wind Speed for Selected stations at $(12 \mathrm{~m})$. 


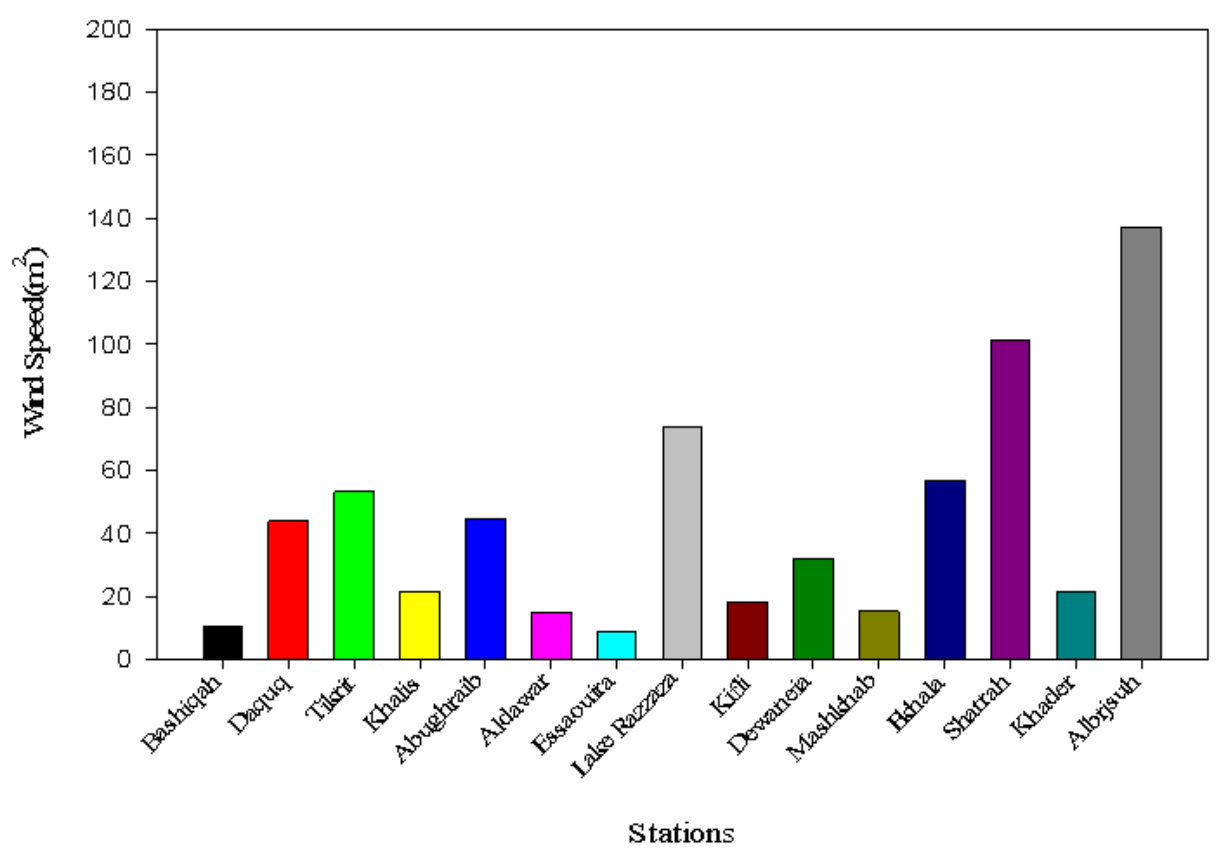

Figure 3. Wind Speed for Selected stations at $(50 \mathrm{~m})$.

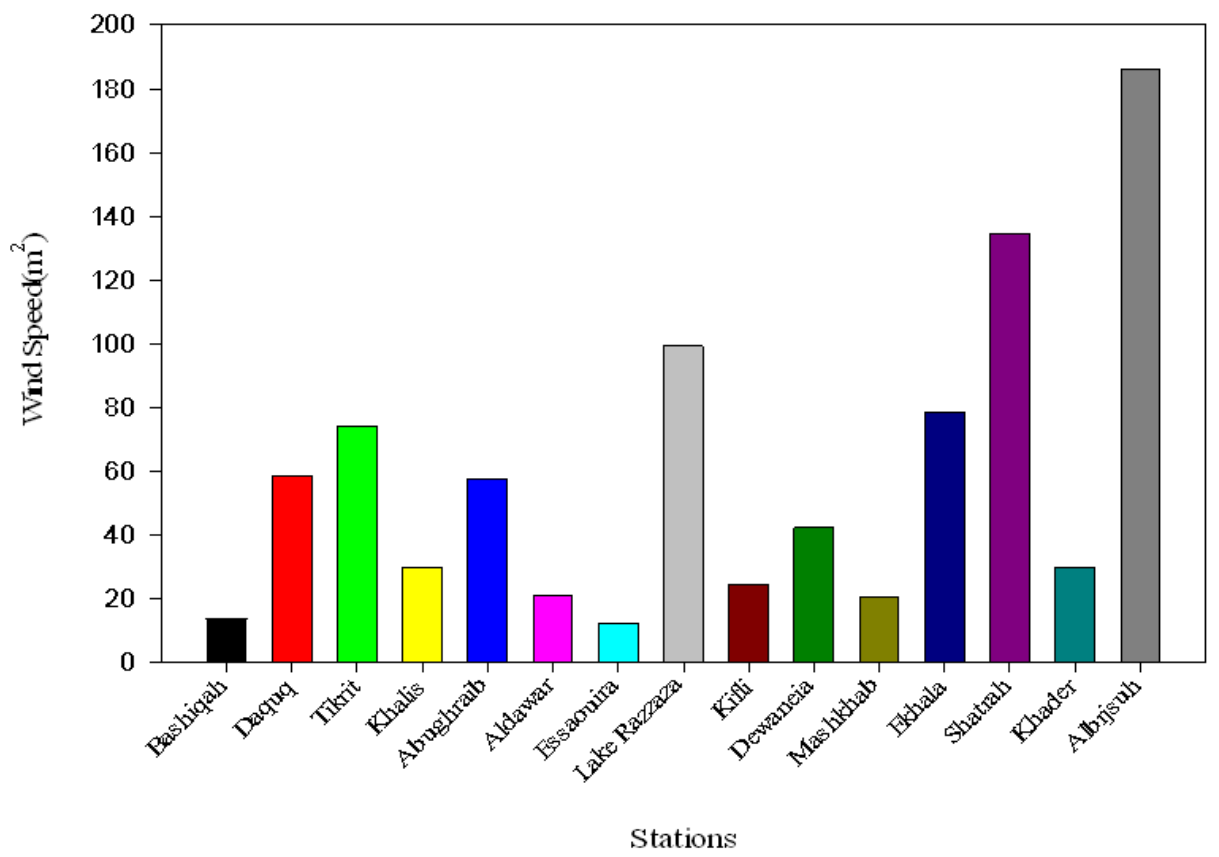

Figure 4. Wind Speed for Selected stations at $(100 \mathrm{~m})$.

By using equations ( 8 and 9) we calculate the Weibull distribution parameters $k$ - Shape parameter and $c(\mathrm{~m} / \mathrm{sec})$-scale parameter in three high $(12,50,100 \mathrm{~m})$ as shown in table (3).

Table 2. Mean Wind Speed $\bar{x}(\mathrm{~m} / \mathrm{s})$ and Stander Deviation (S.D.) at high (12, 50, $100 \mathrm{~m})$ for all Selected Stations.

\begin{tabular}{ccccc}
\hline Stations & Mean and Stander deviation & High (12 m) & High (50 m) & High (100 m) \\
\hline \multirow{2}{*}{ Basrah (Albrjsuh) } & $\bar{x}$ & 4.18 & 5.298 & 5.825 \\
& S.D. & 1.75 & 2.12 & 2.39 \\
Karbla (Lake Razzaza) & $\bar{x}$ & 1.59 & 2.014 & 2.199 \\
Baghdad (Abughraib) & S.D. & 0.85 & 0.98 & 1.12 \\
Kirkuk (Daquq) & $\bar{x}$ & 2.049 & 2.541 & 2.845 \\
& S.D. & 0.80 & 0.99 & 1.1 \\
\hline
\end{tabular}




\begin{tabular}{|c|c|c|c|c|}
\hline Stations & Mean and Stander deviation & High (12 m) & High (50 m) & High (100 m) \\
\hline \multirow{3}{*}{ Dealaa (Khalis) } & S.D. & 1.11 & 1.34 & 1.62 \\
\hline & $\bar{x}$ & 2.224 & 2.736 & 3.037 \\
\hline & S.D. & 0.989 & 1.283 & 1.437 \\
\hline \multirow{2}{*}{ Mayssan (Ekhala) } & $\bar{x}$ & 2.922 & 3.691 & 4.107 \\
\hline & S.D. & 1.511 & 1.85 & 2.079 \\
\hline \multirow{2}{*}{ Muthna (Khader) } & $\bar{x}$ & 3.873 & 4.88 & 5.374 \\
\hline & S.D. & 1.44 & 1.79 & 1.96 \\
\hline \multirow{2}{*}{ Babel (Kifli) } & $\bar{x}$ & 2.108 & 2.629 & 2.903 \\
\hline & S.D. & 0.93 & 1.164 & 1.29 \\
\hline \multirow{2}{*}{ The-Qar (Shatrah) } & $\bar{x}$ & 2.239 & 2.783 & 3.11 \\
\hline & S.D. & 1.01 & 1.24 & 1.36 \\
\hline \multirow{2}{*}{ Anbar (Aldawar) } & $\bar{x}$ & 2.837 & 3.601 & 3.977 \\
\hline & S.D. & 1.18 & 1.51 & 1.57 \\
\hline \multirow{2}{*}{ Wasat (Essaouira) } & $\bar{x}$ & 3.401 & 4.270 & 4.726 \\
\hline & S.D. & 1.422 & 1.770 & 1.940 \\
\hline \multirow{2}{*}{ Salahaldeen (Tikrit) } & $\bar{x}$ & 3.047 & 3.821 & 4.268 \\
\hline & S.D. & 1.23 & 1.600 & 1.700 \\
\hline \multirow{2}{*}{ Qadisiyah (Dewaneia) } & $\bar{x}$ & 2.437 & 3.08 & 3.371 \\
\hline & S.D. & 1.13 & 1.49 & 1.66 \\
\hline \multirow{2}{*}{ Mosul (Bashiqah) } & $\bar{x}$ & 1.77 & 2.243 & 2.244 \\
\hline & S.D. & 0.72 & 0.90 & 0.99 \\
\hline \multirow{2}{*}{ Najaf (Mashkhab) } & $\bar{x}$ & 1.82 & 2.299 & 2.537 \\
\hline & S.D. & 1.00 & 1.27 & 1.40 \\
\hline
\end{tabular}

By using equations ( 3 and 5) we calculated the wind power and wind power density by Weibull distribution at high (12, $50,100 \mathrm{~m}$ ) for all selected stations as shown in table (4)and figure (5), we also chosen the wind turbine $3 \mathrm{kw}$ [9] see table(5).

Table 3. Weibull Parameters at high (12, 50, $100 \mathrm{~m})$ for all Selected Stations.

\begin{tabular}{|c|c|c|c|c|}
\hline Stations & Weibull Parameters & High (12 m) & High (50 m) & High (100 m) \\
\hline \multirow{2}{*}{ Basrah (Albrjsuh) } & $k$ & 2.561 & 2.688 & 2.609 \\
\hline & $c$ & 4.709 & 5.958 & 6.557 \\
\hline \multirow{2}{*}{ Karbla (Lake Razzaza) } & $k$ & 1.947 & 2.156 & 2.054 \\
\hline & $c$ & 1.795 & 2.274 & 2.482 \\
\hline \multirow{2}{*}{ Baghdad (Abughraib) } & $k$ & 2.751 & 2.763 & 2.786 \\
\hline & $c$ & 2.303 & 2.855 & 3.196 \\
\hline \multirow{2}{*}{ Kirkuk (Daquq) } & $k$ & 2.84 & 3.007 & 2.639 \\
\hline & $c$ & 3.27 & 4.149 & 4.477 \\
\hline \multirow{2}{*}{ Dealaa (Khalis) } & $k$ & 2.395 & 2.258 & 2.235 \\
\hline & $c$ & 2.509 & 3.089 & 3.429 \\
\hline \multirow{2}{*}{ Mayssan (Ekhala) } & $k$ & 2.024 & 2.084 & 2.072 \\
\hline & $c$ & 3.298 & 4.167 & 4.636 \\
\hline \multirow{2}{*}{ Muthna (Khader) } & $k$ & 2.908 & 2.96 & 2.98 \\
\hline & $c$ & 4.343 & 5.476 & 6.019 \\
\hline \multirow{2}{*}{ Babel (Kifli) } & $k$ & 2.416 & 2.407 & 2.397 \\
\hline & $c$ & 2.378 & 2.965 & 3.275 \\
\hline \multirow{2}{*}{ The-Qar (Shatrah) } & $k$ & 2.357 & 2.388 & 2.426 \\
\hline & $c$ & 2.526 & 3.14 & 3.507 \\
\hline \multirow{2}{*}{ Anbar (Aldawar) } & $k$ & 2.576 & 2.545 & 2.728 \\
\hline & $c$ & 3.195 & 4.057 & 4.47 \\
\hline \multirow{2}{*}{ Wasat (Essaouira) } & $k$ & 2.566 & 2.578 & 2.614 \\
\hline & $c$ & 3.831 & 4.809 & 5.320 \\
\hline \multirow{2}{*}{ Salahaldeen (Tikrit) } & $k$ & 2.649 & 2.561 & 2.548 \\
\hline & $c$ & 3.428 & 4.304 & 4.802 \\
\hline \multirow{2}{*}{ Qadisiyah (Dewaneia) } & $k$ & 2.267 & 2.172 & 2.134 \\
\hline & $c$ & 2.751 & 3.478 & 3.806 \\
\hline \multirow{2}{*}{ Mosul (Bashiqah) } & $k$ & 2.607 & 2.684 & 2.651 \\
\hline & $c$ & 1.993 & 2.523 & 2.651 \\
\hline \multirow{2}{*}{ Najaf (Mashkhab) } & $k$ & 1.875 & 1.878 & 1.882 \\
\hline & $c$ & 2.05 & 2.59 & 2.651 \\
\hline
\end{tabular}


Table 4. Wind Power Density by Weibull Distribution $\left(w / \mathrm{m}^{2}\right)$ and Wind Power at high $(12,50,100 \mathrm{~m})$ for all Selected Stations.

\begin{tabular}{|c|c|c|c|c|}
\hline Stations & $W P D, W P$ in $\left(w / m^{2}\right)$ & High (12 m) & High (50 m) & High (100 m) \\
\hline \multirow{2}{*}{ Basrah (Albrjsuh) } & WPD by Weibull dis. & 69.7 & 137.2 & 186 \\
\hline & $W P$ & 1181.50 & 2355.01 & 3169.61 \\
\hline \multirow{2}{*}{ Karbla (Lake Razzaza) } & $W P D$ by Weibull dis. & 4.9 & 8.9 & 12.2 \\
\hline & $W P$ & 82.48 & 164.41 & 221.29 \\
\hline \multirow{2}{*}{ Baghdad (Abughraib) } & WPD by Weibull dis. & 7.8 & 14.9 & 20.8 \\
\hline & $W P$ & 136.95 & 272.99 & 367.41 \\
\hline \multirow{2}{*}{ Kirkuk (Daquq) } & WPD by Weibull dis. & 22 & 43.9 & 58.5 \\
\hline & $W P$ & 392.69 & 782.72 & 1053.47 \\
\hline \multirow{2}{*}{ Dealaa (Khalis) } & WPD by Weibull dis. & 11 & 21.5 & 29.7 \\
\hline & $W P$ & 196.52 & 391.72 & 527.22 \\
\hline \multirow{2}{*}{ Mayssan (Ekhala) } & WPD by Weibull dis. & 29 & 56.7 & 78.6 \\
\hline & $W P$ & 503.51 & 1003.61 & 1350.77 \\
\hline \multirow{2}{*}{ Muthna (Khader) } & WPD by Weibull dis. & 51.1 & 101.6 & 134.5 \\
\hline & $W P$ & 836.52 & 1667.39 & 2244.15 \\
\hline \multirow{2}{*}{ Babel (Kifli) } & $W P D$ by Weibull dis. & 9.7 & 18.1 & 24.5 \\
\hline & $W P$ & 154.19 & 307.34 & 413.65 \\
\hline \multirow{2}{*}{ The-Qar (Shatrah) } & WPD by Weibull dis. & 11.4 & 21.7 & 29.8 \\
\hline & $W P$ & 199.58 & 397.82 & 535.43 \\
\hline \multirow{2}{*}{ Anbar (Aldawar) } & WPD by Weibull dis. & 21.7 & 44.7 & 57.5 \\
\hline & $W P$ & 375.94 & 749.35 & 1008.55 \\
\hline \multirow{2}{*}{ Wasat (Essaouira) } & $W P D$ by Weibull dis. & 37.5 & 73.9 & 99.2 \\
\hline & $W P$ & 623.8156 & 1243.4113 & 1673.50 \\
\hline \multirow{2}{*}{ Salahaldeen (Tikrit) } & WPD by Weibull dis. & 26.3 & 53.2 & 73.9 \\
\hline & $W P$ & 437.5615 & 872.1629 & 1173.84 \\
\hline \multirow{2}{*}{ Qadisiyah (Dewaneia) } & WPD by Weibull dis. & 15.2 & 31.8 & 42.3 \\
\hline & $W P)$ & 274.30 & 546.75 & 735.88 \\
\hline \multirow{2}{*}{ Mosul (Bashiqah) } & WPD by Weibull dis. & 5.2 & 10.4 & 13.7 \\
\hline & $W P$ & 84.95 & 169.33 & 227.91 \\
\hline \multirow{2}{*}{ Najaf (Mashkhab) } & $W P D$ by Weibull dis. & 7.6 & 15.2 & 20.4 \\
\hline & $W P$ & 127.66 & 254.46 & 342.48 \\
\hline
\end{tabular}

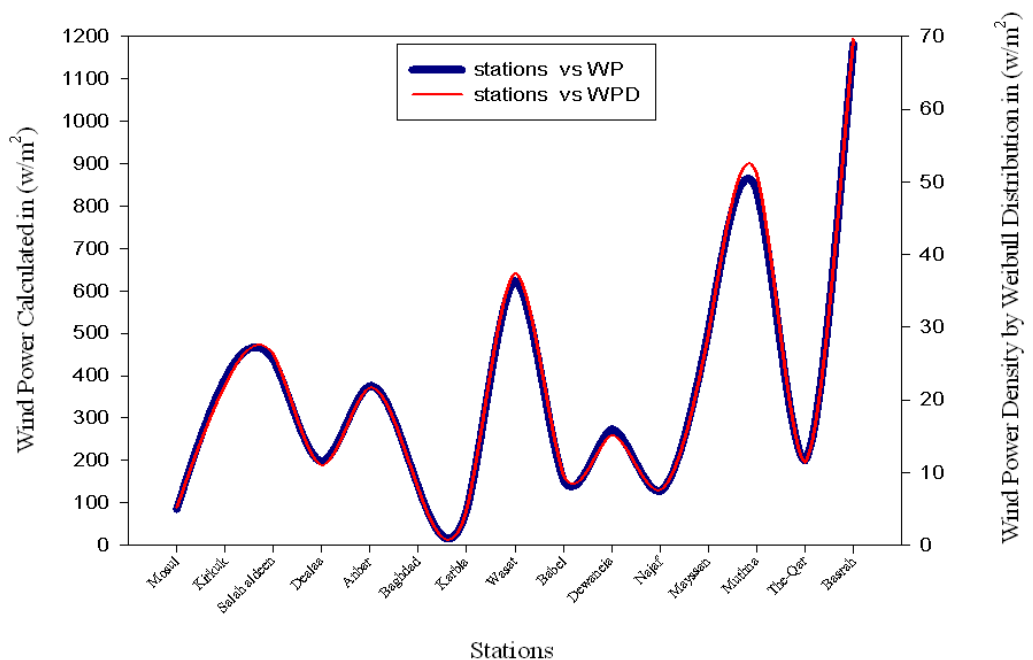

Figure 5. Compare between Wind Power calculated and Wind Power Density by Weibull Distribution. 
Table 5. Some Specifications of Wind Turbine ( $3 k w)$.

\begin{tabular}{ll}
\hline Nominal Power & $3 \mathrm{kw}$ \\
Rotor diameter & $4.5 \mathrm{~m}$ \\
Area swept & $15.89 \mathrm{~m}^{2}$ \\
Maximum power & $4000 \mathrm{w}$ \\
Rated output voltage & $240 \mathrm{v}$ \\
Rated wind speed & $10 \mathrm{~m} / \mathrm{s}$ \\
Start wind speed & $2 \mathrm{~m} / \mathrm{s}$ \\
Maximum wind speed & $45 \mathrm{~m} / \mathrm{s}$ \\
Tower height & $12 \mathrm{~m}$ \\
Number of blades & 3 \\
Rated rooter speed & $220 \mathrm{r} / \mathrm{m}$ \\
\hline
\end{tabular}

Also in this paper we have been employed the relation wind speed and wind power with the time by illustrating a Parameters Liner Regression statistical analysis formula with first order type as show below [10].

$$
\mathrm{f}=\mathrm{y}_{\mathrm{o}}+\mathrm{ax}
$$

Where $f$ is the function for wind speed or wind power calculated, $a$ is the regression slope, $y_{o}$ is the regression constant (equation 11), $\mathrm{x}$ is the number of day. As shown in figures $(6,7$ and 8$)$

$$
\mathrm{y}_{\mathrm{o}}=\frac{\sum_{i=1}^{n}(x i-x)-(f i-f)}{\sum_{i=1}^{n}(x i-x)^{2}}
$$

And for this reason we selected three stations represent north middle and south [Mosul (Bashiqah), Baghdad (Abughraib) and Basrah (Albrjsuh)] in Iraq as shown in tables (6 and 7).

\begin{tabular}{|c|c|c|c|c|c|}
\hline Stations & Parameters Liner regression & Pearson correlation & High (12 m) & High (50 m) & High (100 m) \\
\hline \multirow{3}{*}{ Basrah (Albrjsuh) } & & $\mathrm{R}$ & 0.298 & 0.298 & 0.298 \\
\hline & $\mathrm{y}_{\mathrm{o}}$ & & 5.156 & 6.489 & 7.164 \\
\hline & a & & -0.05 & -0.006 & -0.007 \\
\hline \multirow{3}{*}{ Baghdad (Abughraib) } & & $\mathrm{R}$ & 0.224 & 0.224 & 0.224 \\
\hline & $y_{0}$ & & 2.379 & 2.994 & 3.306 \\
\hline & a & & -0.0018 & -0.0023 & -0.0025 \\
\hline \multirow{3}{*}{ Mosul (Bashiqah) } & & $\mathrm{R}$ & 0.322 & 0.322 & 0.322 \\
\hline & $y_{0}$ & & 2.185 & 2.750 & 3.037 \\
\hline & a & & -0.002 & -0.002 & -0.003 \\
\hline
\end{tabular}

Table 6. Parameters Liner Regression for Wind Speed (WS) at high (12, 50, $100 \mathrm{~m})$.

\begin{tabular}{|c|c|c|c|c|c|}
\hline Stations & Parameters Liner regression & Pearson correlation & High (12 m) & High (50 m) & High (100 m) \\
\hline \multirow{3}{*}{ Basrah (Albrjsuh) } & & $\mathrm{R}$ & 0.255 & 0.255 & 0.255 \\
\hline & $\mathrm{y}_{\mathrm{o}}$ & & 1938.35 & 3863.59 & 5200.00 \\
\hline & a & & -4.124 & -8.221 & -11.064 \\
\hline \multirow{3}{*}{$\begin{array}{l}\text { Baghdad } \\
\text { (Abughraib) }\end{array}$} & & $\mathrm{R}$ & 0.157 & 0.157 & 0.157 \\
\hline & $\mathrm{y}_{\mathrm{o}}$ & & 217.25 & 433.03 & 582.81 \\
\hline & $\mathrm{a}$ & & -0.47 & -0.872 & -1.173 \\
\hline \multirow{3}{*}{ Mosul (Bashiqah) } & & $\mathrm{R}$ & 0.241 & 0.241 & 0.241 \\
\hline & $\mathrm{y}_{\mathrm{o}}$ & & 130.47 & 260.06 & 350.02 \\
\hline & a & & -0.248 & -0.494 & -0.665 \\
\hline
\end{tabular}

Table 7. Parameters Liner Regression for Wind Power (WP) at high (12, 50,100 m). 


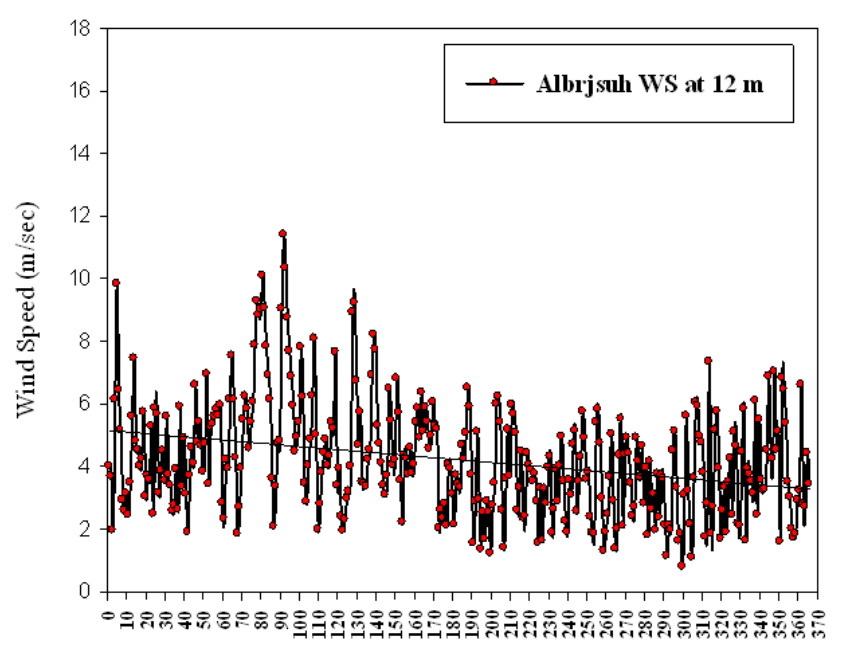

Days
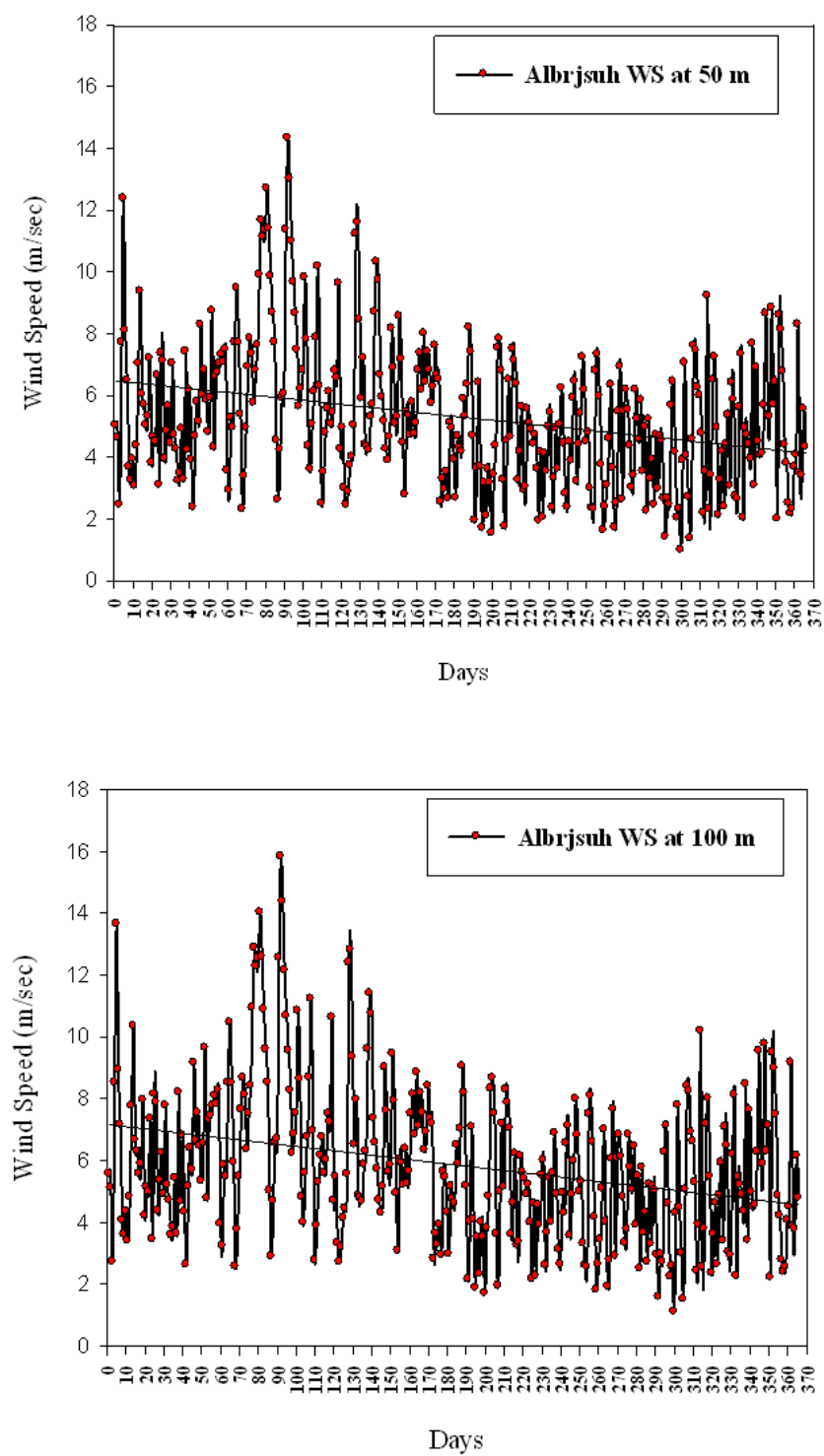
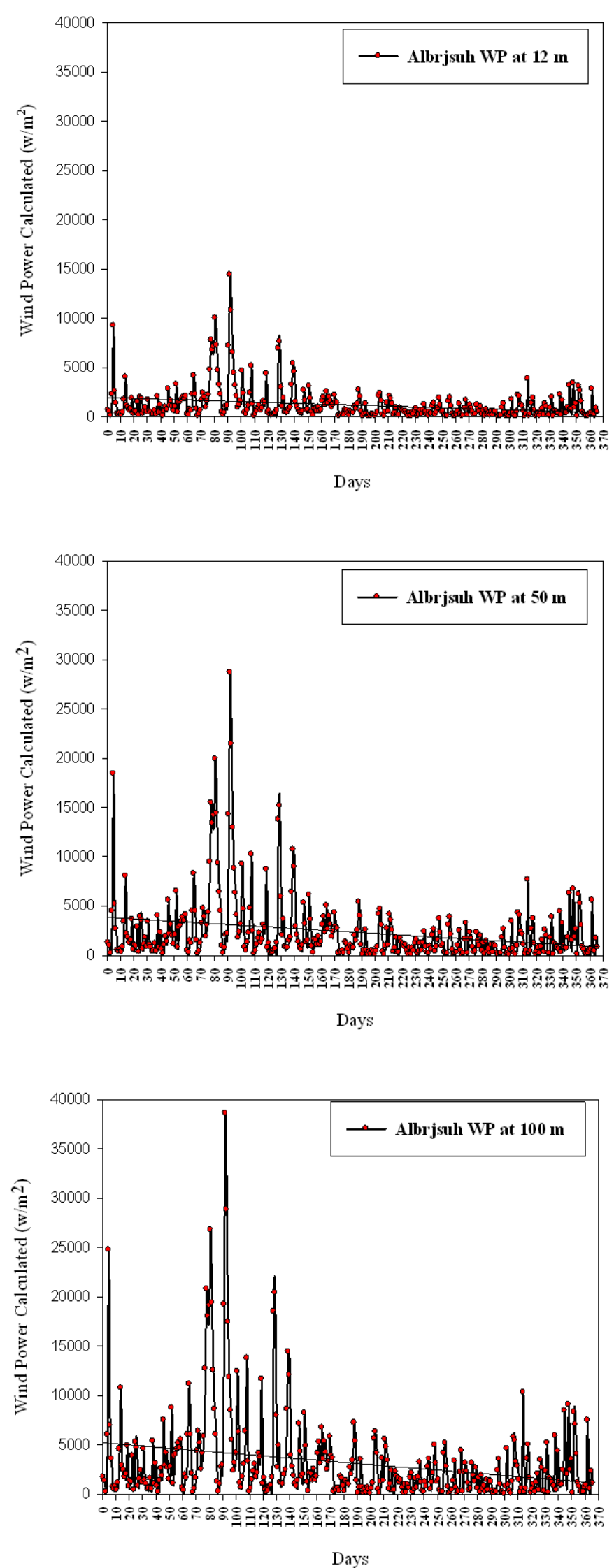

Figure 6. The Day Average of Basrah (Albrjsuh) Station Wind Speed and Wind Power calculated at (12, 50, $100 \mathrm{~m})$. 

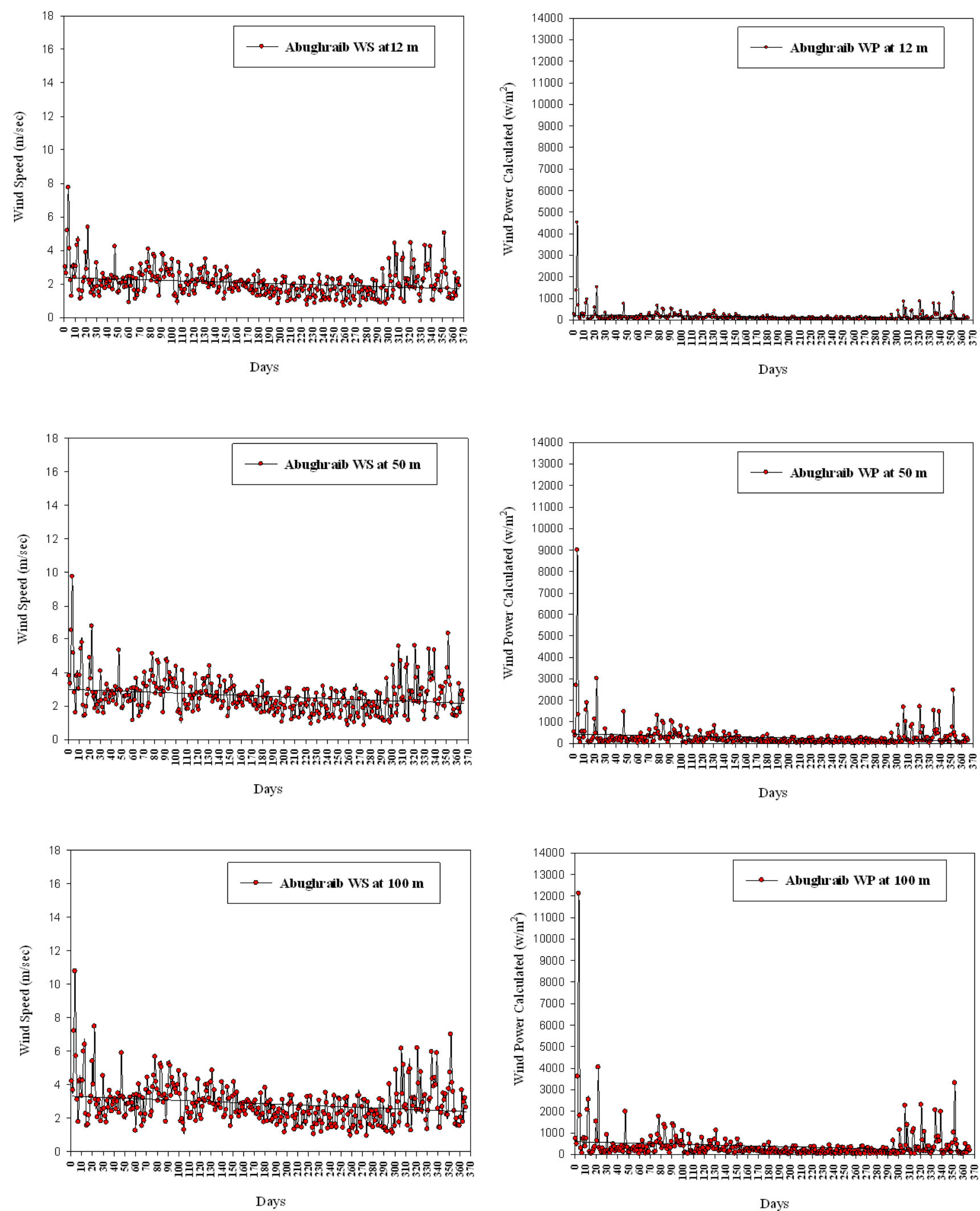

Figure 7. The Day Average of Baghdad (Abughraib) Station Wind Speed and Wind Power calculated at (12, 50, $100 \mathrm{~m}$ ). 

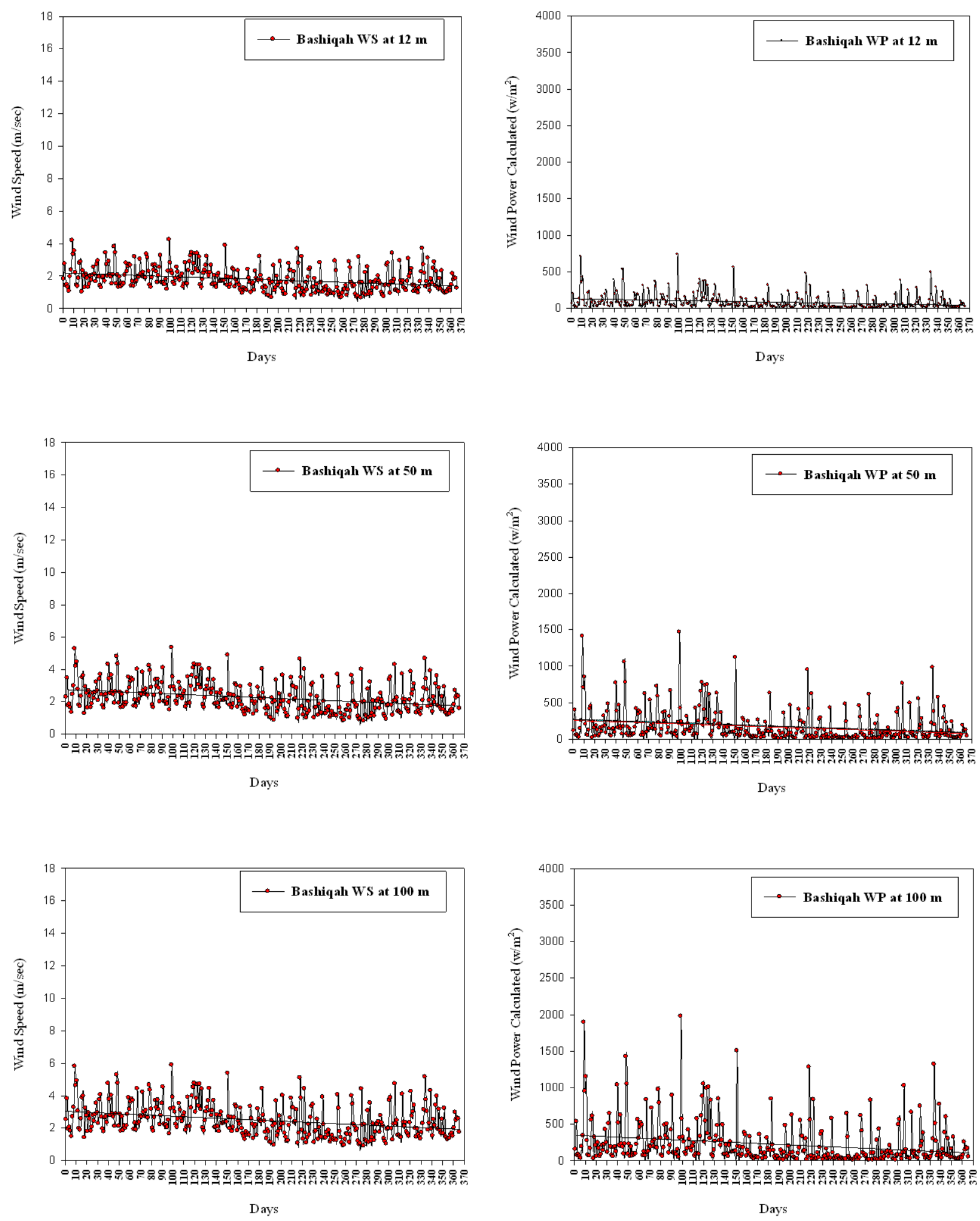

Figure 8. The Day Average of Mosul (Bashiqah) Station Wind Speed and Wind Power calculated at (12, 50, $100 \mathrm{~m})$.

\section{Result and Discussion}

At all the stations under study, the wind power generation and the wind power density can be higher in the south region as the daily average wind speed are strongest during this period and for all heights. The maximum values at Basrah (Albrjsuh), the medium values at Baghdad (Abughraib) and the lowest values in northern region Mosul (Bashiqah).Medium size or small wind turbines can be used to generate electricity in those regions. The true estimation of Weibull parameters is important for the manufacturer of the wind turbines who need to know the 
performance of their turbines "The graphical method", using the real life wind speed data .The highest values foe Weibull parameters at Basrah (Albrjsuh), the medium values at Baghdad (Abughraib) and the lowest values in Mosul (Bashiqah). The regression statistical analysis correlation was found for all stations and the most effective values was in at Basrah (Albrjsuh), the medium values at Baghdad (Abughraib) and the lowest values was Mosul (Bashiqah).

\section{References}

[1] Mix Ma. (1997).“ Adaptive Extremism Control and wind turbine control.' $\mathrm{Ph}$. P. thesis Technical university of Denmark.

[2] Physics of Wind Power.

[3] C. Dunder and D. Inam,) 1996). "The analysis of Wind Data and Wind Energy Potential in Bardirwa." Turkey.

[4] K. Rosen, (1998). " An Assessment of the Potential for utility- scale wind power Generation in Eritrea."
[5] H. Panofsky and J. Dutton, (1984). “Atmospheric Turbulence: models and methods for engineering applications.' Pennsylvania State University: John Wiley and Sons.

[6] Sanusi, Y.K. and Abisoye, S.G., (2011). "Estimation of Wind Energy Potential in Southwestern Nigeria." Pacific Journal of Science and Technology; 12(2):160-166. http://www.akamaiuniversity.us/PJST.htm

[7] Alghou, M. A., Sulaiman, M.Y., B.Z.Azmi and Abd. Wahab, M., (2007). "Wind Energy Potential of Jordan." International Energy Journal; 8:pp.71-78.

[8] Ministry of Agriculture, unpublished data.

[9] Congress of the United States, Congressional Budget Office, (2008). "The Economic Effects of Recent Increases in Energy Prices." Available [Online] at http://www.cbo.gov/ftpdocs/74xx/doc7420/07-21Energy\%20DIST.

[10] Gieleck, Mark i, F. Mayes, and L. Prete., (2008). "Incentives, Mandates, and Government Programs for Promoting Renewable Energy." Available [Online] at http://www.eia.doe.gov/cneaf/solar.renewables/rea_issues/in cent.html. 